Roger Scruton, How to be a Conservative (Londres: Bloomsbury, 2014).

RESEÑA

\title{
ROGER SCRUTON O EL "LIBERALISMO CLÁSICO” DE UN CONSERVADOR INGLÉS
}

\author{
Juan Luis Ossa Santa Cruz \\ Centro de Estudios de Historia Política \\ Universidad Adolfo lbáñez
}

\begin{abstract}
[ $\mathrm{n}$ uno de los pasajes más citados de su libro Reflections on the - French Revolution (1790), el irlandés Edmund Burke se detuvo a definir su concepción de "sociedad": "La sociedad es un contrato. [...] Es una asociación que abarca toda ciencia, todo arte y toda perfección. Como los fines de una asociación así no pueden lograrse sino en muchas generaciones, pasa a ser una asociación no solamente entre seres vivos, sino entre aquellos que están vivos, los que están muertos y aquellos que están por nacer". ${ }^{1}$ Desde entonces, y a pesar de los años y de la mucha agua que ha corrido bajo el puente del pensamiento occidental, dicha frase ha sido considerada como el mejor resumen de lo conservador, y como la crítica más certera a las posiciones rupturistas o revolucionarias. Ahora bien, como todo ismo, el conservadurismo tiene una historia, un presente y un futuro, además de características específi-
\end{abstract}

JuAn LuIS OsSa. Doctor en historia moderna por St Antony's College, Universidad de Oxford. Director ejecutivo del Centro de Estudios de Historia Política de la Universidad Adolfo Ibáñez. Entre sus últimas publicaciones destacan "The Army of the Andes: Chilean and Rioplatense Politics in an Age of Military Organisation", en Journal of Latin American Studies (2014), y el libro Armies, Politics and Revolution. Chile, 1808-1826 (2014). Email: juan.ossa@uai.cl.

${ }^{1}$ He extraído esta traducción de la frase de Burke de un artículo editado por Arturo Fontaine Talavera en Estudios Públicos 9 (1983), 147. 
cas e inherentes a las necesidades y exigencias del lugar desde donde se lo invoca. De ahí que no sea antojadizo volver una y otra vez a analizar y definir sus contornos, misión recientemente llevada a cabo por el reconocido filósofo inglés Roger Scruton.

En How to be a Conservative, ${ }^{2}$ Scruton (2014) estudia principalmente al conservadurismo inglés, por lo que se debe ser consciente de que sus afirmaciones están ancladas en un mundo y una tradición particulares. Su apego a Burke es explícito, señalando que los conservadores "no sólo estudian el pasado: lo heredamos, y las herencias traen consigo tanto derechos de propiedad como deberes fiduciarios. Las cosas por las que luchamos y morimos no deberían ser inútilmente despilfarradas. Ellas pertenecen a otros, que aún no han nacido" (182). Que Scruton sea burkeano no quiere decir, empero, que el conservadurismo del siglo XXI lo entienda como un simple remedo del conservadurismo dieciochesco. Los temas tocados en su libro son muy propios del mundo actual, donde abarca desde el multiculturalismo al socialismo; del transnacionalismo al liberalismo; y del nacionalismo al ambientalismo. De éstos, me detendré en cómo, según el autor, debería reaccionar un conservador inglés ante el socialismo, la religión, la economía, la tradición, el nacionalismo, las asociaciones civiles, la modernidad y el liberalismo. Ésta es una estructura de análisis similar a la que presenta Scruton en su libro, aunque a lo largo de esta reseña discrepo con algunas secciones del mismo.

Lo primero que se debe despejar es que How to be a Conservative no entrega una definición única y estática de lo conservador, ya que una de sus hipótesis implícitas es que el conservadurismo es todo menos lineal y monolítico. Lo más cercano a una definición lo encontramos en el prefacio, donde expone cuál debería ser la posición de un conservador en la actualidad:

El conservadurismo que defenderé nos dice que hemos heredado colectivamente cosas buenas que debemos esforzarnos por mantener. En la situación en que nos encontramos (siendo herederos de la civilización occidental y de su parte angloparlante) somos conscientes de cuáles son dichas cosas. La oportunidad de vivir

${ }^{2}$ Todas las citas a este libro, en adelante, se harán tan sólo con el número de página. 
nuestra vida como deseemos; la seguridad de la ley imparcial, a través de la cual nuestras diferencias son respondidas y nuestras heridas restauradas; la protección de nuestro medio ambiente como un activo compartido, el cual no puede ser controlado o destruido por el antojo de intereses poderosos; la abierta e indagatoria cultura que ha dado forma a nuestros colegios y universidades; los procedimientos democráticos que nos permiten elegir a nuestros representantes y pasar nuestras leyes: éstas y muchas otras cosas nos son familiares y las damos por asumidas. Todas ellas están bajo amenaza. (viii)

De acuerdo con el orden analítico del libro, dichas "cosas buenas" están amenazadas por una serie de "enemigos", el principal de los cuales es el socialismo y el excesivo papel que, según el autor, juega el Estado en la sociedad occidental. A diferencia de otros pensadores, Scruton llegó a esta conclusión no sólo a partir de sus lecturas teóricas de Marx o Lenin, sino a través de su propia experiencia vital en Inglaterra y la antigua Unión Soviética. En Londres, nos cuenta en un capítulo introductorio llamado "My Journey" ("Mi viaje"), se encontró en Birkbeck College con un grupo de colegas liderados por Eric Hobsbawm cuyo principal objetivo era "reconstruir Gran Bretaña bajo el modelo socialista" (5). La revista New Left Review, conocida por introducir un tipo de "humanismo marxista" que tenía como propósito "curar los defectos del modelo soviético", nació precisamente durante esos años en que todo lo que olía o sonaba a "conservatismo" era apuntado como aliado del "imperialismo americano" (5). El aislamiento académico de Scruton en Inglaterra comenzó, entonces, en una fecha tan temprana como la década de 1970. Sin embargo, fue en los territorios bajo la influencia de la Unión Soviética donde paradójicamente alcanzó sus mayores éxitos intelectuales durante esa época. Cuenta Scruton que en un viaje a Polonia y Checoslovaquia en 1979 “descubrió de primera mano lo que [George] Orwell percibió cuando se encontraba luchando junto a los comunistas en la Guerra Civil Española y que expresó en imágenes reveladoras en Nineteen Eighty-Four", esto es, "la traducción en hechos de las ficciones que nadaban en los cerebros de mis colegas marxistas. Entré en Hobsbawmia y sentí el encantamiento maligno de un mundo totalmente desencantado" (10). Fue sólo después de ingresar al círculo de disidentes checos que Scruton encontró un cierto grado de tranqui- 
lidad, además de un cúmulo de colegas con los cuales colaboró a establecer universidades de pregrado en países controlados por el estatismo totalitario de la Unión Soviética.

Es probable que todo conservador europeo compartiría la crítica política de Scruton respecto al rol del Estado. Veremos más adelante que, al igual que Margaret Thatcher, de quien se declara un admirador, Scruton prefiere a la "sociedad civil" por sobre el Estado, una opción compartida también por otros conservadores a lo largo y ancho del mundo occidental (8). "El papel del Estado", sostiene Scruton, "es, o debería ser, menor que el que exigen los socialistas pero mayor del que permiten los liberales clásicos. El Estado tiene un objetivo, que es proteger a la sociedad civil de sus enemigos externos y sus desórdenes internos. No puede ser simplemente el 'Estado vigilante nocturno' defendido por Robert Nozick, ya que la sociedad civil depende de uniones que no pueden ser renovadas sin la disposición colectiva del bienestar" (135). Sin embargo, por mucho que el Estado actúe de vez en cuando como el garante del bienestar de los hombres y mujeres que le dan forma, éste no puede transformarse en "el proveedor universal y regulador propuesto por los igualitaristas, pues el valor y el compromiso emergen de asociaciones autónomas, las cuales únicamente florecen si crecen desde abajo. El Estado, por lo demás, está en condiciones de redistribuir la riqueza únicamente en el entendido de que haya riqueza, y ésta es creada por aquellos que esperan una participación en ella" (135).

Muchos conservadores concordarían también en que la "ilusión socialista" de que el "pobre es pobre porque el rico es rico" (45) no se "mejora" con una mayor intervención del Estado, y que al final de cuentas la mayor "perversión del socialismo no se encuentra en sus desordenadas [topsy-turvy] teorías económicas que tanto fascinaban a Marx, como tampoco en las teorías de justicia social propuesta por pensadores como John Rawls". Más bien, "la real perversión está en una falacia peculiar que ve a la vida en sociedad como una en que el éxito de una persona es el fracaso de la otra" (46).

Otros comentarios, sobre todo en relación con el papel público de la religión y de la economía, serían tomados con bastante más cautela; no sólo por el conservadurismo europeo, sino por conservadores chilenos, dos de cuyas principales características son su ferviente catolicismo y un cierto espíritu economicista. Scruton sostiene efectivamente 
que la religión es un elemento consustancial del conservadurismo, y considera también que el libre mercado es el más correcto generador de riquezas. No obstante, ni la religión ni la economía son fines en sí mismos para él. Como Burke, Scruton es un defensor de la tradición y del reformismo gradualista. Su tradición es la judeocristiana, es decir, una forma de vida en la que la religión actúa como el gran paraguas del mundo occidental, aunque no como el centro vector de la convivencia política. Religión sí, pero instituciones políticas religiosas no, parece decirnos Scruton.

Algo similar puede decirse de su visión de la economía moderna. Sin duda, Scruton acepta que el capitalismo es un sistema no sólo eficiente, sino que además justo. Si en términos políticos Burke es su faro, en economía lo es Adam Smith. Sin embargo, consciente de que Smith no era tanto un economista profesional cuanto un filósofo moral de la economía, Scruton establece - correctamente, a mi manera de veruna diferencia profunda entre la economía como una ciencia de razonamiento instrumental y la economía como la gran ideóloga de la vida moderna (166). A la economía, dice Scruton, no se le puede entregar la responsabilidad única de decidir las políticas públicas, sino que ellas deben zanjarse a partir de un proceso de negociación entre la técnica y la política representativa. El conservadurismo bien entendido, continúa, busca devolver el oikos - es decir, la primera persona plural o el nosotros- a la oikonomia, pues, de lo contrario, la economía "deja de ser una ciencia práctica y se transforma en una ideología casi tan maligna como el marxismo o el fascismo" (167).

El llamado a recobrar la primera persona plural -we, our - se repite a lo largo de How to be a Conservative. El contrato de Burke entre los muertos, los vivos y los que están por nacer le es funcional a Scruton para introducir el argumento de que el conservadurismo está anclado en el nacionalismo y que, en consecuencia, la economía inglesa debería tener un componente nacionalista. En efecto, detrás de su idea en torno al oikos se encuentra una crítica explícita a la existencia misma de la Unión Europea y su consiguiente multiculturalismo económico, llegando incluso a explicar la caída de Margaret Thatcher a partir de sus diferencias con algunos sectores del Partido Conservador por el papel que, según estos últimos, debía jugar la Unión Europea en materias que, a lo largo del mandato de Thatcher, habían sido resueltas desde una perspectiva únicamente nacional. 
Ahora bien, la posición de Scruton sobre este tema no es tanto ideológica cuanto pragmática. Según él, el nacionalismo no debe entenderse como una ideología: "El nacionalismo es peligroso en el mismo sentido que lo son las ideologías", pues tiende a ocupar el espacio de la religión y lleva al verdadero creyente "a venerar la idea nacional y a buscar aquello que en realidad no puede proveer: el fin último de la vida, el camino a la redención y el consuelo de todos nuestros males" (32). Este tipo de nacionalismo se encuentra implícito en la obra del Abate Sieyès y más concretamente en la literatura de la Alemania nazi. El nacionalismo bien entendido, en cambio, estaría en la base del día a día del inglés común corriente, siendo un elemento consustancial de la "identidad inglesa". Una identidad que se ha construido gracias a ciertas convenciones culturales como el simbolismo de la Iglesia de Inglaterra, el parlamentarismo, la monarquía y las universidades Oxbridge. No importa que ya muy pocos ingleses asistan a la iglesia o que se autodenominen como religiosos, pues, como dijera George Orwell en 1941, "la gente común y corriente en Inglaterra" ha prácticamente olvidado "el nombre de Cristo", pero ha mantenido siempre un "profundo tinte de sentimiento cristiano" (180). Scruton no ve nada malo en ello; al final de cuentas, su nosotros nacional no descansa en un nosotros fervientemente religioso o "étnico". Por el contrario,

El Estado nación, como lo concebimos en la actualidad, es el subproducto de la vecindad, formado por una "mano invisible" a partir de los innumerables acuerdos entre personas que hablan el mismo idioma y conviven [diariamente]. Es el resultado de los compromisos establecidos después de muchos conflictos y expresa el acuerdo formado lentamente entre vecinos, tanto para concederse un espacio mutuamente como para proteger dicho espacio como [si se tratara de] un territorio común. (33)

Es interesante el esfuerzo de Scruton por hacer del nacionalismo un componente de la identidad inglesa, así como un factor constitutivo de la sociedad civil asentada en la vecindad. No obstante, permítaseme introducir mi primera discrepancia con el autor. Como se sabe, la identidad es un concepto difícil de definir; de hecho, los análisis en torno suyo derivan generalmente en esencialismos. La inmigración es un buen ejemplo. Por mucho que Scruton utilice argumentos racionales y 
no "ideológicos" cuando señala que la identidad inglesa debe ser resguardada de inmigrantes indeseados, me parece que su postura peca al menos de dos problemas.

En primer lugar, por mucho que la tradición exista y sea defendida, nadie podría decir que ella es inmutable. Inglaterra ha cambiado - muchas veces para mejor - una y mil veces desde que Burke escribió su invectiva contra la Revolución Francesa. Y digo para mejor, pues en diversas ocasiones esas mutaciones se han institucionalizado de abajo hacia arriba, es decir, de la manera en que el propio Scruton dice que se deben realizar los cambios (más de esto señalaré a continuación).

En segundo lugar, los llamados a proteger la identidad inglesa con argumentos culturalistas pueden fácilmente acabar en una defensa de lo que, en realidad, es indefendible. Uno de los logros más significativos de Hitler durante la década de 1930 fue convencer a sus seguidores del "peligro" que representaban los judíos para la economía alemana, al estar la riqueza y el empleo concentrados en manos de dicha comunidad. Lo que comenzó como una diatriba económica derivó, empero, en una persecución cultural — “étnica”, para utilizar una palabra de Scrutoncontra todo lo que oliera a judío. Aun cuando no estoy en condiciones de vaticinar que algo similar podría ocurrir en Inglaterra producto de la inmigración, en especial de origen musulmán, sí creo que la censura de Scruton a los Estados islámicos por fundar sus decisiones políticas en la religión no es del todo convincente para oponerse de plano a la inmigración. Concuerdo en que el gran triunfo de los Estados occidentales fue secularizar sus instituciones políticas, dando a la religión un estatus de importancia aunque siempre en la esfera de lo íntimo. No obstante, ¿qué hacer con los musulmanes no radicalizados y que, a pesar de no querer claudicar de su fe y creencias, consideran a Inglaterra como un buen lugar para vivir y criar a sus hijos? No es fácil la respuesta, pero al menos no debería reducirse a algo tan subjetivo como la identidad ni a la supuesta inmutabilidad de la tradición inglesa. Algo similar puede decirse de la opinión del autor respecto al matrimonio entre homosexuales (142 y siguientes). Si bien la familia occidental se ha construido en base al matrimonio heterosexual, investigaciones actuales remarcan, por un lado, la existencia de diversos tipos de familias y, por otro, que el cariño hacia los hijos difícilmente depende de la orientación sexual de los padres. 
Hay, con todo, un punto sobre el nacionalismo que me parece importante de destacar como algo positivo. Scruton nos recuerda que una de las soluciones adoptadas luego de la Segunda Guerra Mundial para frenar el resurgimiento de regímenes nacionalistas a la usanza del nazismo alemán o el fascismo italiano fue sentar las bases para la futura Unión Europea. La Unión, señala el autor, "surgió desde el convencimiento de que las guerras europeas habían sido causadas por el sentimiento nacional, y que lo que se necesitaba era una nueva y transnacional forma de gobierno que uniera al pueblo bajo un interés compartido en torno a la coexistencia pacífica". No obstante, al derivar de un tratado firmado por los mismos Estados nacionales a los que pretendía superar, la Unión Europea ha sufrido permanentemente de una "crisis de legitimidad" (35). No sólo eso: al ser una suerte de superestructura que depende de una plataforma burocrática incluso más impersonal que la de los Estados nacionales, las acciones de sus miembros no son accountable $e^{3}$ ante los ojos de los ciudadanos. Las leyes pensadas en Bruselas por un grupo pequeño de iluminados en nombre de todo un continente ponen en entredicho la existencia misma de las fronteras que, para bien o para mal, dan vida a los Estados modernos. Con ello, cualquier tratado entre dos Estados nacionales por fuera de la Unión Europea parecería ser ilegítimo, cuestión de suyo compleja si consideramos que, como toda estructura administrativa (la Corte de La Haya incluida), la institucionalidad de la Unión depende del subjetivismo ideológico de quienes la gobiernan. Aunque Scruton no lo explicite, detrás de esto está la idea de que los Estados — nacionales o supranacionales - no son entelequias abstractas. Como plantea la historiadora Annick Lempérière, "sabemos que 'el Estado' no actúa, el Estado no recoge impuestos, no recluta soldados y sabemos que 'la administración de justicia' no es la que administra la justicia. Son hombres muy concretos los que desempeñan todas estas funciones del Estado" (Lempérière 2007, 55). Debido a que son seres humanos los que dan forma al Estado, éstos deben ser accountable ante la ciudadanía; de otra forma, la burocracia se transforma en enemiga de la democracia representativa y en caldo de cultivo para el abuso corrupto del poder.

${ }^{3}$ Aunque los conceptos accountable y accountability podrían ser traducidos como aquello que alude a la responsabilidad pero también a rendir cuentas frente a ojos externos, ninguna de las acepciones que he revisado en castellano me han convencido, por lo que utilizo dichos conceptos en inglés a lo largo del texto. 
Y ya que es tan difícil el accountability cuando se trata de Estados grandes y omnipresentes lo mejor es reducir sus tentáculos; no al grado minimalista del "minarquismo" de Nozick, pero sí hasta el punto de supeditarlos a lo que Scruton llama "asociaciones civiles". Aquí Scruton introduce un punto importante y que, según su análisis, está en el corazón del conservadurismo: la necesidad de contar con una política construida "de abajo hacia arriba". Las asociaciones civiles son el paradigma de esta forma de hacer política, pues la autoridad central no tiene mayor injerencia en decisiones que competen —o deberían competera los ciudadanos comunes y corrientes. El problema, agrega Scruton, es que las asociaciones civiles "han sido crecientemente desplazadas, bajo la presión de elites políticas, managers, partidos e ideologías" (27), provocando que las capas inferiores de la sociedad participen cada vez menos en política. ${ }^{4}$

Lo que ha ocurrido con la educación inglesa en las últimas décadas ayuda a comprender la posición del autor en esta materia. Dice Scruton que desde la década de 1960 el "igualitarismo" imperante llevó a que el gobierno percibiera a "los colegios no como asociaciones para la transmisión del conocimiento, con objetivos internos desarrollados de acuerdo con las necesidades y deseos de sus miembros, sino como instrumentos de ingeniería social" (28). Esto provocó que los currículos, los exámenes y los procesos de admisión a las escuelas y colegios privados fueran objeto de múltiples "revisiones" con el fin de ser funcionales a las metas del gobierno, entre las que destacaban la "eliminación de las distinciones y ventajas injustas, de manera que todos los niños entraran en la sociedad con las mismas oportunidades de una vida digna" (28). Las instituciones educacionales privadas - estandartes de las asociaciones civiles - pasaron, de ese modo, a ser fácilmente manipuladas por el Estado, un ejercicio no muy distinto de lo que ocurre actualmente en Chile desde que la política de subvenciones a los colegios privados comenzara a ser mirada con recelo por las autoridades del Ministerio de Educación.

${ }^{4}$ Es interesante que Scruton ni siquiera nombre a Jesse Norman (2014) —otro defensor de las "sociedades civiles", además de uno de los articuladores ideológicos del gobierno de David Cameron (y quien en más de una oportunidad ha visitado Chile para entregar sus "recetas" a grupos de centroderecha) - entre los "pensadores" conservadores en la actualidad. ¿Podríamos concluir que ser hoy conservador en Inglaterra no es sinónimo de apoyar irrenunciablemente a Cameron y su camarilla de intelectuales? 
Según Scruton, hay asociaciones civiles más relevantes que otras. No toda comunidad, por el sólo hecho de que sus participantes consientan sobre su existencia, merece el mismo respeto. "La verdad en el conservadurismo", dice, "depende de nuestro reconocimiento de que la libre asociación debe ser valorada sólo si ésta es a su vez una fuente de valor; en otras palabras, sólo si es concebida para la realización [de los miembros de la asociación] más que como una mera utilidad o recreación" (132). Es decir, el "verdadero" conservador se diferencia del libertario en cuanto éste último acepta cualquier tipo de asociación civil con tal de que no esté sujeto a las garras del Estado. Interesante la diferenciación, pero, como en otros casos ya analizados, no del todo convincente. ¿Quién o quiénes deciden qué asociación es digna de existir y cuál no? En la última parte del libro Scruton intenta responder esta pregunta, lográndolo a veces, otras simplemente generando en el lector más dudas que certezas. Hay dos cosas desconcertantes o ambiguas en este punto: en primer lugar, una cierta ingenuidad de parte del autor cuando arguye el viejo adagio de que "todo lo que fue pasado fue mejor". En segundo, y conectado con lo anterior, un conflicto no resuelto entre el conservador del siglo XXI y la modernidad.

La ingenuidad de Scruton respecto al papel positivo de las asociaciones civiles del pasado queda retratada en su visión bucólica del funcionamiento de la policía en la Inglaterra de su infancia. Uno podría estar de acuerdo con el autor en que la policía debería existir "no para controlar al individuo, sino para liberarlo" (133). No obstante, sostener que la "famosa postura y ethos" (133) de la policía inglesa de la década de 1950 se debía a su organización local y a que era accountable ante los consejos comunales es olvidar que las policías en nuestro tiempo deben ser más bien accountable a un Estado supra-comunal (ya sea federal o unitario) si pretenden ejercer el monopolio de la fuerza. No basta con que los vecinos conozcan a sus policías, los inviten a tomar el té $\mathrm{y}$, eventualmente, se enamoren de ellos (como se aprecia, por ejemplo, en la serie de la BBC Call the Midwife). Las policías tienen responsabilidades que van mucho más allá de fiscalizar a los vecindarios; tienen como misión lograr que el Estado de derecho sea respetado y, de esa forma, frenar el excepcionalismo legal que supone el abuso de poder, ya sea estatal, gubernamental o local. No veo cómo el orden y la tradición de Scruton podrían defenderse sin el concurso — no necesariamente 
violento- de los cuerpos de policía modernos, y menos que ello pueda lograrse descansando la administración comunal en la buena voluntad de los vecinos.

Me parece que Scruton se empeña en convencernos de que la policía de su infancia era más respetuosa de las libertades individuales porque él tiene una concepción dicotómica de la modernidad. No soy dado a utilizar el concepto de modernidad en mis escritos, pues, al igual como ocurre con el de identidad, es demasiado genérico para dar con una definición concluyente. Aun así, en la argumentación de Scruton encontramos el término, tanto para oponerse al postmodernismo de autores como Foucault y Derrida, como para — valga la paradoja — reprochar aspectos relevantes de la cultura moderna. Scruton acepta ser hijo de la modernidad universalista de la Ilustración, lo cual explica por qué el relativismo posmoderno le es tan huidizo. El autor es especialmente hostil al hecho de que Foucault y sus compañeros "deban su eminencia intelectual no a sus argumentos, sino por dar autoridad a la negación de la autoridad, y a su compromiso absoluto con la imposibilidad de un compromiso absoluto" (83). Nada de sorprendente en este comentario. Lo que sí es sorprendente es que Scruton introduzca una mirada particularmente negativa de la modernidad, es decir, de aquello que le ha permitido cimentar su diatriba contra el posmodernismo. Lo que al parecer quiere decirnos es que la modernidad ilustrada es valiosa si y sólo si ella se queda en el ámbito de la tradición ilustrada. Una opinión válida pero obviamente subjetiva, pues para comprobar esta hipótesis recurre al muy poco objetivo argumento de que la cultura moderna se caracteriza por su "fealdad" y falta de estética. El lector podría coincidir con Scruton en que la arquitectura moderna es extravagante y poco agraciada. Sin embargo, es por todos sabido que la "belleza" ha sido históricamente "sacrificada" por amplios sectores de la sociedad civil (ésa que tanto le gusta a Scruton) para obtener un mayor progreso material (cuestión también aplaudida por el autor). Ése es el caso, por ejemplo, del mall de Castro, en la isla de Chiloé.

Esta visión dicotómica se repite en el último tema que me prometí analizar, aunque en este caso la dicotomía es del todo bienvenida. Dejo para el final las reflexiones de Scruton sobre la relación entre conservadurismo y liberalismo, porque, a diferencia de sus opiniones respecto a los otros ismos, el autor introduce ideas, paradojas y sutilezas del todo 
convincentes; y ya que el libro es una contribución relevante para la filosofía política occidental, me parece justo concluir con lo más rescatable. El capítulo dedicado a "The Truth in Liberalism" comienza con una acertada aclaración: el significado de la palabra "liberalismo" ha mutado muchas veces desde que los diputados en las Cortes de Cádiz comenzaran a utilizarla para referirse a una forma de hacer política contraria al despotismo y a la arbitrariedad. Por supuesto, desde mucho antes pensadores como Locke, Hume o Smith habían utilizado lo que hoy denominaríamos argumentos "liberales" para dar cuenta de sus posiciones. Sin embargo, la explicitación y difusión de su uso es posterior y su significado ha cambiado constantemente a partir de las necesidades concretas de sus exponentes. Ser liberal hoy en Estados Unidos significa estar en la izquierda del espectro político (65), mientras que en Latinoamérica ser liberal es generalmente - aunque no siempre - sinónimo de defender ideas de centroderecha. Esta diferenciación es producto, creo, de la carga económica que se ha tendido a dar al concepto de liberalismo durante las últimas décadas, confundiéndose el "neoliberalismo" con el "liberalismo clásico" de Locke, Burke, Stuart Mill o Isaiah Berlin. Con ello, se ha teñido de economicismo un concepto eminentemente político.

Ahora bien, hay algunos principios políticos clave que cualquier historiador o filósofo debería considerar como liberales clásicos. La tradición constitucional anglosajona —el caso francés es distinto, aunque no es necesario entrar ahora en dichas diferencias - está construida sobre la base de que el poder debe ser limitado: "Aquella tradición ha fijado los puntos principales de la jurisprudencia liberal: la doctrina de la separación de poderes, la teoría de la independencia judicial y la idea procesal de la justicia, según la cual todos los ciudadanos son iguales ante la ley y el juez debe ser imparcial" (70). Los conservadores ingleses no tendrían, según Scruton, mayores problemas en aceptar estos principios liberales; de ahí que las banderas conservadoras de Burke hayan sido muchas veces enarboladas por liberales clásicos. Stuart Mill, por ejemplo, sostenía que "cualesquiera sean nuestros principios morales, viviremos juntos en armonía, respetando la libertad de cada individuo, únicamente si aceptamos que nuestros principios no son, como tales, exigibles como derechos" (76-77). Así, los liberales clásicos proponen que "el Estado puede restringir la libertad del ciudadano, pero sólo en orden a proteger a sus conciudadanos del peligro" (77). 
Este axioma del liberalismo clásico ha perdido relevancia últimamente a raíz del auge del liberalismo igualitarista ("progresista", se diría en Chile), cuya principal arma es la utilización de estructuras estatales con el fin de "defender" a las "minorías". A diferencia de los liberales clásicos (o conservadores ingleses, que en este caso es lo mismo), los liberales igualitaristas ven al Estado como el garante de la libertad de los individuos. A pesar de que discrepo de Scruton en cuanto a que las minorías no puedan exigir ciertos derechos por vía del Estado, concuerdo con él en que el discurso pro minorías tiende a ir de la mano de un muy bajo nivel de tolerancia hacia aquellos que no concuerdan con su forma de pensar. La oposición a la retórica pro minorías suele ser duramente castigada por la academia políticamente correcta a través del ostracismo o, en Estados Unidos, mediante la no obtención del tan mentado tenure. El conservadurismo inglés o liberalismo clásico de Scruton es, en ese sentido, un antídoto contra la moda política e intolerantemente correcta. Nada resume mejor la opinión del autor al respecto que este magnífico párrafo:

El ensayo sobre la tolerancia de Locke de 1689 señaló que la tolerancia de opiniones y formas de vida con las que uno no está de acuerdo es una de las virtudes de la sociedad liberal. Sin embargo, muchos de los que se llaman hoy liberales parecen no comprender bien lo que significa esta virtud. La tolerancia no significa renunciar a todas las opiniones que otros puedan considerar ofensivas. No significa un relativismo fácil de llevar o una creencia de que "todo vale". Por el contrario, significa aceptar el derecho de otros a pensar y actuar de una manera que tú desapruebas. Significa estar preparado para proteger a personas de la discriminación negativa incluso cuando odias lo que dicen y lo que sienten. (170)

Algo similar ocurre con la democracia: al final de cuentas, los ciudadanos deben aceptar a sus gobernantes democráticamente elegidos aunque los odien. De ahí la relevancia de contar con una oposición activa, así como la de entender por qué el papel de la negociación es tan importante en un sistema democrático. Aceptar el compromiso entre gobierno y oposición es, pues, consustancial a una adecuada forma de hacer política, un argumento que debería ser compartido por todo aquel 
que crea que el liberalismo es el mejor remedio contra el abuso del poder burocrático.

Termino estas páginas haciendo un llamado a los lectores a acercarse a esta obra; no es necesario ser "conservador" para disfrutarla. A pesar de que he criticado algunas de las ideas de Scruton, estoy convencido de que su lectura es indispensable para cualquiera interesado en la filosofía del siglo XXI. Su conservadurismo, por lo demás, es mucho más que simplemente conservador. Quizás la mayor riqueza del libro esté en que muchos podemos sentirnos cómodos con una o más de sus afirmaciones, cuestión que convierte a este conservador inglés en uno de los mejores exponentes del liberalismo clásico y del pensamiento político moderno.

\section{REFERENCIAS CITADAS}

Burke, Edmund. 1983. "Selección de escritos políticos", editados por Arturo Fontaine T. Estudios Públicos 9: 143-170.

Lempérière, Annick. 2007. "La historiografía del Estado en Hispanoamérica. Algunas reflexiones". En Ensayos sobre la nueva historia política de América Latina, siglo XIX, coordinado por Guillermo Palacios. México D. F.: El Colegio de México.

Norman, Jesse. 2014. La Gran Sociedad. Santiago: Instituto de Estudios de la Sociedad.

Scruton, Roger. 2014. How to be a Conservative. Londres: Bloomsbury. EP 